\title{
UJI KUALITAS AIR PADA SUMBER MATA AIR WAIPIDI DESA WAIRASA KECAMATAN UMBU RATU NGGAY BARAT KABUPATEN SUMBA TENGAH
}

\author{
Maria S. Seran ${ }^{1}$, Yanti Daud ${ }^{1}$, dan Willem A. Blegur ${ }^{2}$ \\ 1.Program Studi Pendidikan Biologi, Fakultas Keguruan dan IImu Pendidikan, Universitas \\ Kristen Artha Wacana Kupang \\ 2 Program Studi Biologi, Fakultas Pertanian, Universitas Timor, Kefamenanu-NTT \\ Corresponding author : Wattyseran32@gmail.com
}

\begin{abstract}
ABSTRAK
Penelitian ini bertujuan untuk menguji kualitas air pada sumber Mata Air Waipidi, Desa Wairasa Kecamatan, Umbu Ratu Nggay Barat, Kabupaten Sumba Tengah dengan uji 3 parameter yaitu fisik, kimia, dan biologi. Metode yang digunakan dalam penelitian ini adalah deskriptif kuantitatif dengan membandingkan data hasil pengukuran dari masing-masing parameter air dengan nilai baku mutu PP No. 82 Tahun 2001. Berdasarkan hasil penelitian pada Mata Air Waipidi, hasil analisis uji kualitas air ditemukan parameter yang memenuhi standar baku mutu yaitu: parameter fisik meliputi: Suhu $\left(23^{\circ} \mathrm{C}\right)$, TDS $(187 \mathrm{mg} / \mathrm{L})$, TSS $(\mathrm{O}, 0024$ $\mathrm{mg} / \mathrm{L})$; parameter kimia meliputi: $\mathrm{pH}(7,52 \mathrm{mg} / \mathrm{L}), \mathrm{BOD}(0,32 \mathrm{mg} / \mathrm{L})$, nitrat $(5,5 \mathrm{mg} / \mathrm{L})$, nitrit $(0,049$ $\mathrm{mg} / \mathrm{L})$, sulfat $(7 \mathrm{mg} / \mathrm{L})$, dan parameter biologi meliputi: uji total coliform $(<1,8 \mathrm{ml})$. Parameter yang tidak memenuhi standar baku mutu yaitu: parameter kimia yang meliputi: $\mathrm{DO}(4,77 \mathrm{mg} / \mathrm{L})$, besi $(0,77 \mathrm{mg} / \mathrm{L})$, mangan $(0,117 \mathrm{mg} / \mathrm{L})$, fosfat $(0,54 \mathrm{mg} / \mathrm{L})$, klorin $(0,24 \mathrm{mg} / \mathrm{L})$, sianida $(0,14$ $\mathrm{mg} / \mathrm{L})$, dan tembaga $(0,45 \mathrm{mg} / \mathrm{L})$. Faktor-faktor yang menyebabkan beberapa indikator tidak memenuhi standar baku mutu air disebabkan oleh limbah dari irigasi pertanian, pembusukan daun, dan aktivitas alam seperti erosi, dan pelapukan bebatuan. Mata air Waipidi dikategorikan tidak memenuhi standar baku mutu air kelas 1 berdasarkan PP No. 82 tahun 2001 yang dapat digunakan sebagai air minum namun mata air Waipidi disarankan untuk digunakan sebagai prasarana/sarana rekreasi air, pembudidayaan ikan air tawar, peternakan, dan mengairi budidaya tanaman.
\end{abstract}

Kata kunci : Mata Air Waipidi, Parameter Air, Baku Mutu Air.

\begin{abstract}
This research is aimed to test the quality of water in Waipidi spring, Wairasa Village, Umbu Ratu Nggay Sub-district, Central Sumba regency with three parameters experiment, respectivef physical, chemistry and biology. The method used in this research is quantitative descriptive by comparing the measurement data of each water parameter with the PP standard quality value No. 82 of 2001. Based on the result the research in Waipidi spring water analysis result, that which fulfil the standard mutuality were : temperature $\left(23^{\circ} \mathrm{C}\right)$, TDS $(187 \mathrm{mg} / \mathrm{L}), \mathrm{TSS}$ $(0,0024 \mathrm{mg} / \mathrm{L}), \mathrm{pH}(7,52 \mathrm{mg} / \mathrm{L}), B O D(0,32 \mathrm{mg} / \mathrm{L})$, nitrate $(5,5 \mathrm{mg} / \mathrm{L})$, nitrit $(0,049 \mathrm{mg} / \mathrm{L})$, sulphate $(7 \mathrm{mg} / \mathrm{L})$, and total experiment coliform $(<1,8 \mathrm{ml})$, whereas the standard quality which was unfulfiied are : DO $(4,77 \mathrm{mg} / \mathrm{L})$, iron $(0,77 \mathrm{mg} / \mathrm{L})$, manganese $(0,117 \mathrm{mg} / \mathrm{L})$, phosphate $(0,54 \mathrm{mg} / \mathrm{L})$, chlorine $(0,24 \mathrm{mg} / \mathrm{L})$, cynide $(0,14 \mathrm{mg} / \mathrm{L})$ and copper $(0,45 \mathrm{mg} / \mathrm{L})$. The factors that caused some indicators which fulfilled the quality standard was caused by compost heap, decaying leafs and nature activity like erosion and the moldy rocks. Waipidi spring water has to meet the standard quality of first class of water regulation according to goverment act no PP no. 822001 but the result showed that Waipidi water spring cannot fullfiled the standard, but Waipidi spring water then suggested to be used as be infrastructure water recreation, cultivation of fresh water fish, husbandry animal irigation plant.
\end{abstract}

Keywords : Waipidi Spring Water, water parameter, quality standard water. 


\section{Latar Belakang}

\section{PENDAHULUAN}

Air merupakan senyawa kimia yang sangat penting bagi kehidupan manusia dan makhluk lainnya dengan fungsi yang tidak akan dapat digantikan oleh senyawa lain seperti $\mathrm{CO}^{2}$, alkohol, dan glukosa. Seluruh kegiatan yang dilakukan manusia membutuhkan air, mulai dari membersihkan diri, membersihkan tempat tinggalnya, menyiapkan makanan, dan minuman sampai dengan aktivitas lainnya. Seiring dengan naiknya jumlah penduduk serta laju pertumbuhannya, semakin naik pula laju pemanfaatan sumber-sumber air. Air juga merupakan bahan yang penting bagi kehidupan. Tanpa air kehidupan di alam ini tidak dapat berlangsung, baik manusia, hewan, maupun tumbuhan (Suryani, 2004). Meningkatnya kebutuhan air ini disebabkan oleh jumlah penduduk dunia yang makin bertambah, juga sebagai akibat peningkatan taraf hidupnya yang diikuti oleh peningkatan kebutuhan air untuk keperluan rumah tangga, industri, rekreasi, dan pertanian (Achmad, 2004 ).

Kegiatan industri, dosmetik, dan kegiatan lain berdampak negatif terhadap sumber daya air, yaitu menyebabkan penurunan kualitas air. Penurunan kualitas air akan menurunkan daya guna, hasil guna, produktivitas, daya dukung, dan daya tampung dari sumber daya air yang akhirnya menurunkan kekayaan sumber daya alam (Effendi, 2003). Air yang digunakan untuk keperluan sehari-hari sebaiknya adalah air yang memenuhi kriteria sebagai air bersih untuk digunakan yang kualitasnya dapat diketahui dengan melakukan pengujian tertentu terhadap air tersebut. Pengujian yang dilakukan adalah uji fisika, uji kimia, dan uji biologi untuk mengetahui dan menjamin kualitas air yang diinginkan dalam kondisi alamiah tetap sesuai peruntukannya (Waluyo, 2007).

Kabupaten Sumba Tengah yang terletak di wilayah Propinsi Nusa Tenggara Timur dengan kondisi topografi wilayah pada umumnya didominasi oleh perbukitan kapur atau karst. Wilayah ini meskipun diliputi oleh kegersangan dengan curah hujan yang kurang, akan tetapi memiliki sungaisungai maupun sumber mata air yang cukup. Salah satu Kecamatan di Sumba Tengah yang memiliki sumber mata air yaitu Kecamatan Umbu Ratu Nggay Barat.

Kecamatan Umbu Ratu Nggay Barat memiliki beberapa sumber mata air. Salah satu dari mata air tersebut yaitu Mata air Waipidi berlokasi di Desa Wairasa. Masyarakat di Desa Wairasa menggunakan sumber mata air untuk memenuhi kebutuhan sehari-hari seperti minum, mandi, mencuci, peternakan, dan pengairan lahan pertanian. Peningkatan aktifitas masyarakat di sekitar mata air yang dilakukan secara langsung dan tidak langsung dapat mempengaruhi kualitas air mata air Waipidi.

Mata air Waipidi belum diuji kualitasnya sehingga perlu dilakukan uji kualitas air, baik kualitas fisik, kualitas kimiawi maupun kualitas biologi sehingga tercapai kualitas air yang diinginkan sesuai peruntukannya untuk menjamin agar kondisi air tetap dalam kondisi alamiahnya. Tujuan dari penelitian ini adalah untuk menguji kualitas air pada sumber mata air Waipidi, Desa Wairasa, Kecamatan Umbu Ratu Nggay Barat, Kabupaten Sumba Tengah ditinjau dari parameter fisik, kimia, dan biologi berdasarakan Peraturan Pemerintah No.82 Tahun 2001 tentang pengelolaan kualitas air dan pengendalian pencemaran lingkungan.

\section{Tempat dan Waktu Penelitian}

\section{METODE PENELITIAN}

Pengambilan sampel dilakukan di Mata Air Waipidi Desa Wairasa Kecamatan Umbu Ratu Nggay Barat Kabupaten Sumba Tengah dan diuji di Laboratorium Dinas Kesehatan Lingkungan Hidup Kabupaten Sumba Tengah, dilakukan pada bulan Januari sampai bulan Maret 2019.

\section{Alat dan Bahan Penelitian}

\section{Alat penelitian}

Alat yang digunakan untuk menguji kualitas air antara lain: termometer, cawan petri, pompa vakum, oven, timbangan analitik, gelas beker, neraca analitik, kertas saring, spatula, spektrofotometer, vorteks, $\mathrm{pH}$ meter, pipet volume, labu erlenmeyer, hot plate, tabung durham, inkubator, jarum ose, autoklaf, lampu spritus, dan pipet volum, 
2. Bahan

Jurnal pendidikan dan Sains Biologi

Volume 2(2) 2019 (57-64)

Bahan-bahaan yang digunakan dalam penelitian uji kualitas air antara lain: Sampel air dari sumber mata air, Aqua bidestilata steril, BGLBB, LTB tipis, LTB tebal, Ferrous Iron reagent powder pillow, cuver® 1 reagent powder pillow, NitriVer® 3 nitrate powder pillow, NitraVer ${ }^{\circledR} 5$ nitrate powder pillow, cyaniver® cyanide 3 reagent powder pillow, Cyaniver ${ }^{\circledR}$ Cyanide 4 Reagent Powder Pillow, Cyaniver ${ }^{\circledR}$ Cyanide 5 reagent powder pillow, Reagent ascorbit acid powder pillow, Alkaline cyanide reagent, PAN indikator solution $0,1 \%$, Chlorine reagent powder pillow, SulfaVer® 4 reagent powder pillows, Phosphate powder pillow, kapas.

\section{Metode Penelitian}

Metode yang digunakan dalam penelitian ini adalah metode deskriptif kuantitatif.

\section{Parameter yang diukur}

Parameter fisik : Suhu, Total Dissolve Solid (TDS), Total Suspended Solid (TSS); Parameter Kimia: besi $(\mathrm{Fe})$, tembaga $(\mathrm{Cu})$, nitrat $\left(\mathrm{NO}_{3}\right)$, nitrit, sianida $(\mathrm{Cn})$, mangan $(\mathrm{Mn})$, phospat $\left(\mathrm{PO}_{4}\right)$, klorin (Cl), sulfat, pH (Potencial of Hydrogen), DO (Dissolved Oxygen), BOD (Biological Oxygen Demand); dan Parameter Mikrobiologi : total coliform.

\section{Prosedur Penelitian}

\section{Tahap Persiapan}

a. Survei lapangan untuk mengamati dan menentukan lokasi pengambilan sampel.

b. Menyiapkan alat dan bahan yang akan digunakan dalam penelitian.

c. Pengambilan sampel.

2. Tahap Pengukuran Sampel

\section{a. Temperatur Air Permukaan}

Termometer raksa langsung dicelupkan ke dalam sampel uji air dan biarkan 2-5 menit sampai termometer menunjukkan nilai yang stabil kemudian catat pembacaan skala tanpa mengangkat termometer dari dalam air ( SNI 06-6989.23-2005).

\section{b. Padatan Terlarut (TDS)}

Cawan petri ditimbang menggunakan timbangan analitik, catat hasil (sebagai berat awal) kemudian, Cawan disteril dalam oven selama 1 jam pada suhu $180^{\circ} \mathrm{C}$. Tuangkan sampel ke dalam gelas kimia sebanyak $50 \mathrm{ml}\left(\mathrm{V}_{1}\right)$, dan $20 \mathrm{ml}$ aqua bidestilata steril pada gelas kimia $\left(\mathrm{V}_{2}\right)$, Siapkan pompa vakum. Sampel dituangkan ke dalam gelas ukur, setelah itu sampel dituangkan ke dalam cawan lalu dimasukkan ke dalam oven, biarkan selama \pm 2 jam (sampai kering) pada suhu $180^{\circ} \mathrm{C}$. Angkat cawan tersebut kemudian ditimbang, catat hasil (sebagai berat akhir) (SNI 06-6989.27-2005).

Perhitungan TDS menggunakan rumus :

Berat akhir - berat awal $\times 10^{6}$

Volume uji

\section{c. Padatan Tersuspensi (TSS)}

Kertas saring ukuran 5,5 milimikro disimpan di atas kaca arloji, ditimbang menggunakan timbangan analitik, catat hasil (sebagai berat awal), disterilkan di dalam oven selama 1 jam pada suhu $180^{\circ} \mathrm{C}$. Tuangkan sampel ke dalam gelas kimia sebanyak $350 \mathrm{ml}$ lalu siapkan pompa vakum, kertas saring disimpan di bawah corong buchner lalu dijepit, Sampel dituangkan ke dalam buchner flask melalui corong buchner. Angkat kertas saring tersebut kemudian ditimbang, catat hasil (sebagai berat akhir) (SNI 06-6989.3-2004).

\section{Perhitungan}

mg TSS per liter $=A-B \times 1000$

Keterangan :

$$
\text { Volume uji }
$$

A adalah berat kertas saring + residu kering, $(\mathrm{mg})$

d. $\mathbf{p H}$

$\mathrm{B}$ adalah berat kertas saring, $(\mathrm{mg})$.

Sampel dituangkan ke dalam gelas kimia, hidupkan Waterproof (program pH) kemudian celupkan ke dalam sampel (gelas kimia). Biarkan beberapa menit sampai layar menunujukkan hasil akhir yang stabil, catat hasil (SNI 06-6989.11-2004). 


\section{e. Oksigen Terlarut (DO)}

Sampel dituangkan ke dalam gelas kimia, kemudian hidupkan Waterproof (program DO), celupkan ke dalam sampel (gelas kimia). Biarkan sampai layar menunujukkan hasil akhir, Catat hasil $\left(\mathrm{DO}_{0}\right)$, (Multi Parameter Portable).

\section{f. Jumlah Ogsigen Terlarut (BOD)}

Nilai $\mathrm{BOD}$ didapat dari selisih antara $\mathrm{DO}_{0}$ dan $\mathrm{DO}_{5}$, untuk mendapatkan nilai $\mathrm{BOD}$ maka sampel diinkubasi selama 5 hari, (Multi Parameter Portable).

\section{g. Besi (Fe)}

Masukan $10 \mathrm{~mL}$ sampel air ke dalam kuvet sampel, tambahkan Ferrous Iron Reagent Powder Pillows kemudian homogenkan hingga tercampur. Dibiarkan bereaksi selama 5 menit kemudian masukkan $10 \mathrm{~mL}$ aqubides ke dalam kuvet blanko. Masukkan kuvet blanko ke dalam dudukan kuvet (spektrofotometer) dengan garis menghadap ke kanan. Tekan ZERO, layar akan menunjukkan $0,00 \mathrm{mg} / \mathrm{L} \mathrm{Fe}^{2+}$. Keluarkan kuvet blanko, bersihkan kuvet sampel lalu masukkan ke dalam dudukan kuvet ditutup kemudian tekan read, catat hasil yang ada pada layar. Pengukuran pada panjang gelombang $510 \mathrm{~nm}$.

\section{h. Tembaga $\left(\mathrm{Cu}^{2-}\right)$}

Siapkan $10 \mathrm{ml}$ sampel dan masukan ke dalam kuvet sampel, tambahkan 1 bungkus cuVer 2 AccuVac Ampul. Homogenkan sampel, kemudian bersihkan kuvet dibiarkan bereaksi selama 2 menit. Kemudian masukkan kuvet blanko ke dalam dudukan kuvet (spektrofotometer). Tekan zero, layar akan menunjukkan 0,00mg/L $\mathrm{Cu}^{2-}$. Keluarkan kuvet blanko, bersihkan kuvet sampel lalu masukkan ke dalam dudukan kuvet ditutup kemudian tekan read, catat hasil yang ada pada layar. Pengukuran pada panjang gelombang $560 \mathrm{~nm}$.

\section{i. Nitrat $\left(\mathrm{NO}_{3}{ }^{-}\right)$}

Masukkan $10 \mathrm{~mL}$ sampel kedalam kuvet sampel kemudian Tambahkan 1 bungkus Nitraver 5 reagent Nitrate Powder Pillow ke dalam sampel yang sudah disiapkan. Dibiarkan bereaksi selama 5 menit, homogenkan kemudian tuangkan $10 \mathrm{~mL}$ aquabides ke kuvet blanko dan masukkan ke dalam dudukan kuvet. Keluarkan kuvet blanko, bersihkan kuvet sampel lalu masukkan ke dalam dudukan kuvet ditutup kemudian tekan read, catat hasil yang ada pada layar. Pengukuran pada panjang gelombang $500 \mathrm{~nm}$.

\section{j. Nitrit $\left(\mathrm{NO}_{2}^{-}\right)$}

Tuangkan $10 \mathrm{~mL}$ sampel ke dalam kuvet sampel, tambahkan 1 bungkus NitriVer 3 Reagent Nitrit Powder Pillow, dibiarkan bereaksi selama 20 menit kemudian tuangkan $10 \mathrm{~mL}$ sampel ke dalam kuvet yang kedua. Masukkan kedalam dudukan kuvet. Bersihkan kuvet sampel lalu masukkan ke dalam dudukan kuvet ditutup kemudian tekan read, catat hasil yang ada pada layar. Pengukuran pada panjang gelombang $507 \mathrm{~nm}$.

\section{k. Sianida (Cn)}

Masukkan $10 \mathrm{~mL}$ sampel ke dalam kuvet kemudian tambahkan 1 bungkus CyaniVer 3 Reagent Powder Pillow. Tambahkan 1 bungkus CyaniVer 4 Reagent Powder Pillow, kemudian tambahkan 1 bungkus CyaniVer 5 Reagent Powder Pillow. Siapkan kuvet blanko yang berisi $10 \mathrm{~mL}$ aquabides dan masukkan ke dalam dudukan kuvet. Keluarkan kuvet blanko, bersihkan kuvet sampel lalu masukkan ke dalam dudukan kuvet ditutup kemudian tekan read, catat hasil yang ada pada layar. Pengukuran pada panjang gelombang $612 \mathrm{~nm}$.

\section{Mangan (Mn)}

Masukkan $10 \mathrm{~mL}$ sampel ke kuvet sampel, tambahkan 1 bungkus Ascorbic Acid Powder Pillow. Tambahkan 10 tetes Reagent Alkaline-Cynida secara, kemudian tambahkan 12 tetes PAN Indicator Selution ke kuvet sampel. Tekan timer_ok dan biarkan bereaksi selama 2 menit dan masukkan ke dalam dudukan kuvet (spektrofotometer). Keluarkan kuvet blanko, bersihkan kuvet sampel lalu masukkan ke dalam dudukan kuvet ditutup kemudian tekan $R E A D$, catat hasil yang ada pada layar. Pengukuran pada panjang gelombang $560 \mathrm{~nm}$.

\section{m. Phosphat $\left(\mathrm{PO}_{4}{ }^{3-}\right)$}

Masukkan $10 \mathrm{~mL}$ sampel ke dalam kuvet, Tambahkan 1 bungkus PhosVer 3 Reagent Powder Pillow. kuvet ditutup dan di homogenkan selama 20 detik agar Powder Pillow tidak terlalu larut sempurna. tekan timer_ok dibiarkan bereaksi selama 2 menit kemudian Masukkan kuvet blanko ke dalam dudukan kuvet (spektrofotometer). Bersihkan kuvet sampel 


\section{Indigenous Biologi \\ Jurnal pendidikan dan Sains Biologi \\ Volume 2(2) 2019 (57-64)}

lalu masukkan ke dalam dudukan kuvet ditutup kemudian tekan read, catat hasil yang ada pada layar. Pengukuran pada panjang gelombang $880 \mathrm{~nm}$.

n. Klorin $(\mathbf{C l})$

Masukkan $10 \mathrm{~mL}$ sampel ke dalam kuvet sampel yang sudah disiapkan, tambahkan 1 bungkus DPD Free Chlorine Powder Pillow ke dalam sampel. Kemudian siapkan kuvet blanko dengan $10 \mathrm{~mL}$ aquabides, masukkan kedalam dudukan kuvet (spektrofotometer). Keluarkan kuvet blanko, bersihkan kuvet sampel lalu masukkan ke dalam dudukan kuvet ditutup kemudian tekan read, catat hasil yang ada pada layar. Pengukuran pada panjang gelombang $530 \mathrm{~nm}$.

\section{o. Sulfat}

Masukkan $10 \mathrm{~mL}$ sampel ke dalam kuvet sampel, tambahkan 1 bungkus SulfaVer 4 Reagent Powder Pillow kedalam sampel. Tekan timer_ok dan biarkan bereaksi selama 5 menit, masukkan kuvet blanko yang berisi $10 \mathrm{~mL}$ aquabides dan masukkan ke dalam dudukan kuvet (spektrofotometer). Keluarkan kuvet blanko, bersihkan kuvet sampel lalu masukkan kedalam dudukan kuvet ditutup kemudian tekan read, catat hasil yang ada pada layar. Pengukuran pada panjang gelombang $450 \mathrm{~nm}$.

\section{p. Total Coliform}

\section{1) Pembuatan Media}

a) LTB Tipis

Steril pipet volum $5 \mathrm{ml}$ dalam oven selama 1 jam pada suhu $180^{\circ} \mathrm{C}$, kemudian timbang LTB 0,5\% tipis sebanyak 17,8 gr. Masukkan ke dalam gelas kimia berukuran $500 \mathrm{ml}$ tambahkan aqua bidestilata steril, homogenkan menggunakan hot plate. Setalah itu, larutan LTB dimasukkan ke dalam tabung reaksi yang sudah dimasukkan tabung durham menggunakan pipet volume. Beri kertas label (LTB tipis), sterilkan dalam autoklave pada suhu $121^{\circ} \mathrm{C}$.

b) LTB Tebal

Steril pipet volum $10 \mathrm{ml}$ dalam oven selama 1 jam pada suhu $180^{\circ} \mathrm{C}$, lalu timbang LTB 1,5\% tebal sebanyak 53,4 gr. Masukkan LTB ke dalam gelas kimia berukuran 500 $\mathrm{ml}$ tambahkan aqua bidestilata steril. Homogenkan menggunakan hot plate. Larutan LTB dimasukkan ke dalam tabung reaksi yang sudah dimasukkan tabung durham menggunakan pipet volume. Beri kertas label (LTB tebal), sterilkan dalam autoklave pada suhu $121^{\circ} \mathrm{C}$.

c) BGLBB

Steril pipet volum $10 \mathrm{ml}$ dalam oven selama 1 jam pada suhu $180^{\circ} \mathrm{C}$, lalu timbang BGLBB sebanyak 20 gr. Masukkan ke dalam gelas kimia berukuran 500 ml tambahkan aqua bidestilata steril, homogenkan menggunakan hot plate. Larutan BGLBB dimasukkan ke dalam tabung reaksi yang sudah dimasukkan tabung durham sebelumnya menggunakan pipet volume. Beri kertas label (BGLBB), kemudian steril dalam autoklaf pada suhu $121^{\circ} \mathrm{C}$.

2) Inokulasi sampel

Masukkan $10 \mathrm{ml}$ sampel ke dalam tabung reaksi LTB tebal, $1 \mathrm{ml}$ sampel ke dalam tabung reaksi LTB tipis, dan $0,1 \mathrm{ml}$ sampel ke dalam tabung reaksi LTB tipis menggunakan pipet volume, beri kertas label $(10 \mathrm{ml}$ tebal, $1 \mathrm{ml}$ tipis, $0,1 \mathrm{ml}$ tipis),Masukkan tabung reaksi ke dalam inkubator dan diinkubasi selama 48 jam. Hitung tabung reaksi yang terdapat bakteri (memiliki gelembung dalam tabung durham). Pindahkan sampel ke dalam tabung reaksi BGLBB menggunakan jarum ose $(2 \mathrm{x}$ jarum ose), diinkubasi selama 48 jam, kemudian hitung tabung BGLBB yang memiliki bakteri, sesuaikan dengan tabel MPN (Standard Methods for The Examination Of Water and Wastewater).

\section{Teknik Analisis Data}

Data yang diperoleh dianalisis secara deskriptif kuantitatif dengan membandingkan data hasil pengukuran dari masing-masing parameter air dengan nilai baku mutu PP No. 82 Tahun 2001 tentang pengelolaan kualitas air dan pengendalian pencemaran air. 


\section{Gambaran Umum Mata Air Waipidi}

\section{HASIL DAN PEMBAHASAN}

Mata air Waipidi terletak di Desa Wairasa Kecamatan Umbu Ratu Nggay Barat, Kabupaten Sumba Tengah. Letak Mata Air Waipidi berada pada posisi: 09035'36,41" Lintang Selatan (LS) dan $119^{0} 35^{\prime} 23,65^{\prime \prime}$ Bujur Timur (BT). Mata Air Waipidi terletak $\pm 200 \mathrm{~m}$ dari pemukiman warga. Mata air ini dikelilingi berbagai jenis tumbuhan seperti mangga, bambu, lantoro, paku, dan rerumputan, juga terdapat ikan yang ada pada mata air tersebut. Letak Mata Air Waipidi berdekatan dengan lahan persawahan dan perkebunan masyarakat. Sumber mata air ini digunakan oleh masyarakat untuk memenuhi kebutuhan mereka sehari-hari seperti: minum, masak, mandi, mencuci, mengairi lahan pertanian, dan kebutuhan untuk ternak .

\section{Hasil Penelitian Kualitas air pada Mata Air Waipidi}

Hasil analisis kukalitas air pada sumber mata air Waipidi Desa Wairasa, Kecamatan Umbu Ratu Nggay Barat, Kabupaten Sumba Tengah yang dibandingkan dengan kriteria baku mutu air dalam lampiran PP nomor 82 tahun 2001 kelas I dan kelas II, tentang pengelolaan kualitas air dan pengendalian pencemaran air.

Tabel 1. Hasil penelitian Uji Kualitas Air Pada Mata Air Waipidi

\begin{tabular}{|c|c|c|c|c|c|}
\hline $\begin{array}{l}\text { Param- } \\
\text { eter }\end{array}$ & $\begin{array}{l}\text { Sat } \\
\text { ua } \\
n\end{array}$ & Hasil & $\begin{array}{l}\text { Baku } \\
\text { Mutu } \\
\text { No. } \\
\text { Tahur } \\
2001 \\
\text { Kelas }\end{array}$ & $\begin{array}{r}\text { PP } \\
82 \\
\end{array}$ & $\begin{array}{l}\text { Metode } \\
\text { Pengujian }\end{array}$ \\
\hline & & & 1 & 2 & \\
\hline \multicolumn{6}{|l|}{ FISIKA } \\
\hline $\begin{array}{l}\text { Temper } \\
\text { atur }\end{array}$ & ${ }^{\circ} \mathrm{C}$ & 23 & \pm 3 & & $\begin{array}{l}\text { SNI 06- } \\
6989.23- \\
2005\end{array}$ \\
\hline $\begin{array}{l}\text { Residu } \\
\text { Terlarut } \\
\text { (TDS) }\end{array}$ & $\begin{array}{l}\mathrm{mg} / \\
\mathrm{L}\end{array}$ & 187 & $\begin{array}{l}100 \\
0\end{array}$ & $\begin{array}{l}100 \\
0\end{array}$ & $\begin{array}{l}\text { SNI 06- } \\
6989.27- \\
2005 \\
\end{array}$ \\
\hline $\begin{array}{l}\text { Residu } \\
\text { Tersusp } \\
\text { ensi } \\
\text { (TSS) }\end{array}$ & $\begin{array}{l}\mathrm{mg} / \\
\mathrm{L}\end{array}$ & $\begin{array}{l}0,00 \\
24\end{array}$ & 50 & 50 & $\begin{array}{l}\text { SNI 06- } \\
6989.3- \\
2004\end{array}$ \\
\hline \multicolumn{6}{|l|}{ KIMIA } \\
\hline $\mathrm{Ph}$ & & 7,52 & $6-9$ & & $\begin{array}{l}\text { SNI 06- } \\
6989.11- \\
2004\end{array}$ \\
\hline DO & $\begin{array}{l}\mathrm{mg} / \\
\mathrm{L}\end{array}$ & $4,77^{*}$ & 6 & 4 & $\begin{array}{l}\text { Multi } \\
\text { Parameter } \\
\text { Portabel }\end{array}$ \\
\hline BOD & $\begin{array}{l}\mathrm{mg} / \\
\mathrm{L}\end{array}$ & 0,32 & 2 & 3 & $\begin{array}{l}\text { Multi } \\
\text { Parameter } \\
\text { Portabel }\end{array}$ \\
\hline $\begin{array}{l}\text { Besi } \\
(\mathrm{Fe})\end{array}$ & $\begin{array}{l}\mathrm{mg} / \\
\mathrm{L}\end{array}$ & $0,77^{*}$ & 0,3 & $(-)$ & $\begin{array}{l}\text { Hach } \\
\text { Method } \\
8008 \\
\text { Powder } \\
\text { Pillow }\end{array}$ \\
\hline $\begin{array}{l}\text { Tembag } \\
\text { a }(\mathrm{Cu})\end{array}$ & $\begin{array}{l}\mathrm{mg} / \\
\mathrm{L}\end{array}$ & $0,45^{*}$ & $\begin{array}{l}0,0 \\
2\end{array}$ & $\begin{array}{l}0,0 \\
2\end{array}$ & $\begin{array}{l}\text { Hach } \\
\text { Method } \\
\text { 8506Powde } \\
\text { r Pillow }\end{array}$ \\
\hline $\begin{array}{l}\text { Nitrit } \\
\text { Sebagai } \\
\mathrm{N}\end{array}$ & $\begin{array}{l}\mathrm{mg} / \\
\mathrm{L}\end{array}$ & $\begin{array}{l}0,04 \\
9\end{array}$ & $\begin{array}{l}0,0 \\
6\end{array}$ & $\begin{array}{l}0,0 \\
6\end{array}$ & $\begin{array}{l}\text { Hach } \\
\text { Method } \\
8507\end{array}$ \\
\hline
\end{tabular}

\begin{tabular}{|c|c|c|c|c|c|}
\hline & & & & & $\begin{array}{l}\text { Powder } \\
\text { Pillow }\end{array}$ \\
\hline $\begin{array}{l}\text { NO3 } \\
\text { Sebagai } \\
\mathrm{N}\end{array}$ & $\begin{array}{l}\mathrm{mg} / \\
\mathrm{L}\end{array}$ & 5,5 & 10 & 10 & $\begin{array}{l}\text { Hach } \\
\text { Method } \\
8039 \\
\text { Powder } \\
\text { Pillow }\end{array}$ \\
\hline $\begin{array}{l}\text { Sianida } \\
(\mathrm{CN})\end{array}$ & $\begin{array}{l}\mathrm{mg} / \\
\mathrm{L}\end{array}$ & $0,14^{*}$ & $\begin{array}{l}0,0 \\
2\end{array}$ & $\begin{array}{l}0,0 \\
2\end{array}$ & $\begin{array}{l}\text { Hach } \\
\text { Method } \\
8527 \\
\text { Powder } \\
\text { Pillow }\end{array}$ \\
\hline $\begin{array}{l}\text { Mangan } \\
(\mathrm{Mn})\end{array}$ & $\begin{array}{l}\mathrm{mg} / \\
\mathrm{L}\end{array}$ & $\begin{array}{l}0,11 \\
7^{*}\end{array}$ & 0,1 & $(-)$ & $\begin{array}{l}\text { Hach } \\
\text { Method } \\
8149 \\
\text { Powder } \\
\text { Pillow }\end{array}$ \\
\hline $\begin{array}{l}\text { Total } \\
\text { Phosph } \\
\text { at } \\
\text { sebagai } \\
\text { P }\end{array}$ & $\begin{array}{l}\mathrm{mg} / \\
\mathrm{L}\end{array}$ & $0,54^{*}$ & 0,2 & 0,2 & $\begin{array}{l}\text { Hach } \\
\text { Method } \\
8048 \\
\text { Powder } \\
\text { Pillow }\end{array}$ \\
\hline $\begin{array}{l}\text { Klorin } \\
\text { Bebas }\end{array}$ & $\begin{array}{l}\mathrm{mg} / \\
\mathrm{L}\end{array}$ & $0,24^{*}$ & $\begin{array}{l}0,0 \\
3\end{array}$ & $\begin{array}{l}0,0 \\
3\end{array}$ & $\begin{array}{l}\text { Hach } \\
\text { Method } \\
8021 \\
\text { Powder } \\
\text { Pillow }\end{array}$ \\
\hline Sulfat & $\begin{array}{l}\mathrm{mg} / \\
\mathrm{L}\end{array}$ & 7 & 400 & $(-)$ & $\begin{array}{l}\text { Hach } \\
\text { Method } \\
8051 \\
\text { Powder } \\
\text { Pillow }\end{array}$ \\
\hline \multicolumn{6}{|c|}{ MIKROBIOLOGI } \\
\hline $\begin{array}{l}\text { Total } \\
\text { Coliform }\end{array}$ & $\begin{array}{l}\mathrm{Jml} \\
/ 10 \\
0 \\
\mathrm{ml}\end{array}$ & $\leq 1,8$ & $\begin{array}{l}100 \\
0\end{array}$ & $\begin{array}{l}500 \\
0\end{array}$ & $\begin{array}{l}\text { Standard } \\
\text { Methods for } \\
\text { The } \\
\text { Examinatio } \\
\text { n Of Water } \\
\text { and } \\
\text { Wastewater }\end{array}$ \\
\hline
\end{tabular}




\section{Indigenous Biologi \\ Jurnal pendidikan dan Sains Biologi \\ Volume 2(2) 2019 (57-64)}

Keterangan : *) :Tidak memenuhi baku mutu

(-) : Tidak memiliki nilai

\section{Parameter Fisik}

\section{a. Suhu}

Suhu pada suatu perairan dipengaruhi oleh berbagai faktor seperti, intensitas cahaya matahari, dan pertukaran panas antara air dengan udara sekelilingnya. Semakin besar cahaya yang diterima oleh badan air, semakin tinggi suhu dan begitupun sebaliknya, semakin kecil cahaya yang diterima oleh badan air semakin rendah suhu air tersebut (Mukarromah, 2016).

Hasil uji suhu air pada mata air Waipidi adalah dari $23^{\circ} \mathrm{C}$. Suhu mata air Waipidi memenuhi standar baku mutu menurut PP nomor 82 tahun 2001 kelas I adalah deviasi 3 . Batasan deviasi 3 dapat diartikan sebagai $\pm 3^{\circ} \mathrm{C}$ dari suhu normal air alamiah. Artinya, jika suhu $(\mathrm{T})$ normal air $25^{\circ} \mathrm{C}$, maka kriteria kelas I sampai kelas III membatasi suhu (T) air di kisaran $22^{\circ} \mathrm{C}-28^{\circ} \mathrm{C}$ (Tabel 1). Suhu pada Mata Air Waipidi dikategorikan dalam suhu normal disebabkan karena, pepohonan yang ada di sekitar badan mata air tidak menutupi badan mata air Waipidi sehingga proses penyerapan cahaya dapat berlangsung dengan baik.

b. Total Disolved Solid (TDS)

Penyebab tingginya TDS dalam suatu perairan disebabkan oleh air buangan yang sering mengandung sabun, deterjen, dan surfaktan yang larut dalam air misalnya air buangan yang berasal dari limbah rumah tangga dan sumber-sumber alami seperti daun dan lumpur (Fajarini, 2014).

Hasil pengukuran nilai TDS Mata Air Waipidi adalah $187 \mathrm{mg} / \mathrm{L}$ sedangkan standar kriteria baku mutu air PP nomor 82 tahun 2001 kelas I adalah 1000 mg/L (Tabel 1). Nilai TDS di mata air Waipidi memenuhi standar kriteria baku mutu, disebabkan karena hasil buangan air yang sering mengandung sabun dan deterjen yang masuk ke dalam badan mata air Waipidi, masih tergolong rendah atau tidak mencemari badan air. Sesuai pengamatan di sekitar mata air, masyarakat menggunakan sumber mata air ini untuk memenuhi kebutuhan mereka seperti mandi maupun mencuci, tidak secara langsung dari sumber mata air, tetapi dari aliran mata air yang sudah dibuat penampung, dengan menggunakan batu di sekitar aliran mata air.

\section{c. Total Suspended Solides (TSS)}

TSS menyebabkan air menjadi keruh dan menghalangi masuknya cahaya matahari ke dalam air serta mengganggu proses fotosintesis tumbuhan akuatik. TSS juga disebabkan oleh lumpur, bahan koloid, organik, tumbuhan dan fitoplankton yang dapat meningkatkan tahap kekeruhan air, akibat padatan tidak terlarut dan tidak dapat langsung mengendap. Kandungan TSS yang lebih tinggi disebabkan oleh aktivitas pembukaan lahan dan pengikisan tanah (Miefthawati, 2014 ).

Hasil pengukuran kadar TSS pada Mata Air Waipidi adalah $0,0024 \mathrm{mg} / \mathrm{L}$ sedangkan standar kriteria baku mutu air PP nomor 82 tahun 2001 kelas I adalah 50 mg/L. Nilai TSS pada mata air Waipidi memenuhi standar kriteria baku mutu, hal ini karena mata air Waipidi memiliki air yang cenderung jernih. Mata Air Waipidi belum dipengaruhi atau belum tercemar oleh aktivitas masyarakat di sekitar mata air misalnya kegiatan pertanian sekitar mata air.

\section{Parameter Kimia}

\section{a. Potential of Hidrogen $(\mathrm{pH})$}

Larutan netral mempunyai $\mathrm{pH}=7$, asam mempunyai $\mathrm{pH}<7$ dan larutan yang bersifat basa mempunyai $\mathrm{pH}>7$. Nilai $\mathrm{pH}$ bersifat basa disebabkan oleh basa yang di keluarkan oleh tanaman kayu yang terdapat di sekitar mata air (Hanafiah, 2007 dalam Khatun, 2016). Jika pH lebih kecil dari 6,5 atau lebih besar dari 9,2 akan mengkorosi pipa-pipa air dan dapat mengubah beberapa senyawa kimia menjadi racun yang berbahaya bagi kesehatan manusia (Fajarini, 2014).

Berdasarkan hasil analisis uji kualitas air pada mata air Waipidi nilai $\mathrm{pH}$ adalah 7,52 sedangkan standar kriteria baku mutu air PP nomor 82 tahun 2001 kelas I adalah 6-9 
(Tabel 1). Mata air Waipidi memenuhi standar kriteria baku mutu. Mata air ini tergolong dalam larutan yang bersifat basa, disebabkan oleh keadaan lingkungan sekitar mata air yang terdapat berbagai jenis tumbuhan, sehingga hasil aktivitas dari tumbuhan sekitar mata air dapat mempengaruhi nilai $\mathrm{pH}$ mata air Waipidi.

\section{b. DO (Disolved Oxigen)}

Kadar oksigen dalam suatu perairan, semakin besar nilai DO maka semakin baik kualitas airnya. Semakin rendah nilai DO, dimungkinkan air tersebut telah terkontaminasi atau tercemar. Oksigen mempunyai peranan penting dalam oksidasi dan reduksi bahan organik untuk mengurangi beban pencemaran secara alami maupun secara aerobik untuk memurnikan air buangan (Salmin, 2000).

Hasil pengukuran nilai DO uji kualitas air pada mata air Waipidi adalah 4,77 mg/L sedangkan standar kriteria baku mutu air PP nomor 82 tahun 2001 kelas I adalah $6 \mathrm{mg} / \mathrm{L}$ (Tabel 1). Nilai DO pada mata air Waipidi tidak memenuhi kriteria baku mutu kelas 1. Kadar DO yang rendah pada mata air Waipidi diduga disebabkan masuknya bahan pencemar yang berasal dari aktivitas masyarakat di sekitar mata air, sehingga diperlukan oksigen untuk memurnikan kembali bahan pencemar tersebut. Selain itu, rendahnya DO disebabkan karena mata air Waipidi memiliki aliran air yang tenang sehingga penyerapan udara yang masuk dalam mata air rendah. Kadar DO pada Mata air Waipidi dikategorikan masuk dalam kriteria baku mutu air kelas II. Sehingga disarankan kepada masyarakat pengguna mata air Waipidi untuk tidak menggunakan air tersebut sebagai air minum karena telah tercemar.

\section{c. Biologycal Oxygen Demand (BOD)}

BOD menunjukkan jumlah oksigen terlarut yang dibutuhkan oleh organisme hidup, untuk menguraikan atau mengoksidasi bahan-bahan buangan di dalam air. Jika konsumsi oksigen tinggi, maka semakin kecil sisa oksigen terlarut di dalam air, berarti kandungan bahan buangan yang membutuhkan oksigen adalah tinggi (Fajarini, 2014).

Hasil pengukuran nilai BOD uji kualitas air pada mata air Waipidi adalah $0,32 \mathrm{mg} / \mathrm{L}$ sedangkan standar kriteria baku mutu air PP nomor 82 tahun 2001 kelas I adalah $2 \mathrm{mg} / \mathrm{L}$ (Tabel 1). Nilai BOD pada mata air Waipidi memenuhi standar kriteria baku mutu, disebabkan karena masuknya bahan pencemar dalam badan mata air Waipidi masih tergolong rendah. Bahan pencemar tersebut dapat bersumber dari bahan organik di sekitar lokasi mata air seperti, tumbuhan, dan hewan yang sudah mengalami pembusukan juga dapat berasal dari hasil buangan dari limbah pertanian.

\section{d. Besi (Fe)}

Besi dalam air bersumber dari dalam tanah itu sendiri juga dapat berasal dari sumber lain diantaranya dari larutan pipa besi, reservior air dari besi dan endapan buangan industri Tingginya kandungan besi (Fe) berhubungan dengan keadaan struktur tanah sebagian besar unsur Besi terdapat pada tanah yang mengandung batuan sedimen yang mengandung oksida besi, karbonat, dan sulfida (Sudadi, 2003 dalam Utomo dkk, 2016).

Berdasarkan hasil analisis uji kualitas air pada mata air Waipidi nilai besi adalah 0,77 mg/L sedangkan standar kriteria baku mutu air PP nomor 82 tahun 2001 kelas I adalah $0,3 \mathrm{mg} / \mathrm{L}$ (Tabel 1). Kadar besi mata air Waipidi tidak memenuhi standar kriteria baku mutu. Kadar besi yang tinggi pada mata air Waipidi, disebabkan oleh jarak antara mata air dengan saluran air menuju lahan persawahan sangat dekat, sehingga logam besi cor yang terdapat di dalam saluran air tersebut, diduga mengalami pengkaratan dan dapat meresap masuk ke dalam badan mata air, pada saat hujan atau terjadi erosi. Selain itu penyebab tingginya kadar besi di mata air Waipidi disebabkan oleh keadaan struktur tanah sekitar mata air yang yang pada umummnya didominasi oleh tanah yang karst atau mengandung bebatuan. Kada besi pada mata air Waipidi dikategorikan tidak memenuhi kriteria baku mutu air kelas I, II, III maupun kelas IV. Mata air Waipidi tidak layak dimanfaatkan sebagai air minum, sehingga disarankan kepada masyarakat pengguna mata air Waipidi untuk tidak mengkonsumsi air tersebut karena kadar besi yang tinggi dalam suatu perairan sangat berbahaya dan dapat menyebabkan penyakit.

\section{e. Tembaga $(\mathrm{Cu})$}

Keberadaan tembaga di perairan dapat berasal dari berbagai sumber, antara lain dari kegiatan pertambangan, rumah tangga, limbah pertanian, limbah industri, pembusukan 


\section{Indigenous Biologi \\ Jurnal pendidikan dan Sains Biologi \\ Volume 2(2) 2019 (57-64)}

daun, dan penguraian mikroorganisme yang terjadi di alam (Fitriyah dkk, 2013). Tembaga pada kadar yang lebih besar dari $1 \mathrm{mg} / \mathrm{L}$ akan menyebabkan rasa tidak enak pada lidah dan dapat menyebabkan ginjal, muntaber, pusing, lemah, dan dapat menimbulkan kerusakan pada hati. Dalam dosis rendah menimbulkan rasa kesat, warna dan korosi pada pipa (Joko, 2010).

Berdasarkan hasil analisis uji kualitas air pada mata air Waipidi nilai tembaga adalah 0,45 mg/L sedangkan standar kriteria baku mutu air PP nomor 82 tahun 2001 kelas I adalah $0,02 \mathrm{mg} / \mathrm{L}$ (Tabel 1). Kadar tembaga pada mata air Waipidi tidak memenuhi standar kriteria baku mutu kelas 1. Kadar tembaga yang tinggi pada mata air Waipidi diduga berasal dari pengkaratan peralatan pertanian, yang terbuat dari logam tembaga, yang sering dibersihkan di sekitar lokasi mata air, sehingga air cucian tersebut dapat meresap masuk ke badan mata air. Selain itu juga dapat berupa kawat dan kaleng yang dibuang di sekitar lokasi mata air, yang kemudian meresap masuk ke badan mata air. Kadar besi pada mata air Waipidi dikategorikan tidak memenuhi standar kriteria baku mutu air kelas I, II, III maupun IV. Sehingga disarankan kepada masyarakat pengguna air dari mata air Waipidi untuk tidak mengkonsumsi air tersebut karena kadar tembaga pada mata air Waipidi sudah melebihi ambang batas dan dapat menimbulkan penyakit jika dikonsumsi terus menerus.

\section{f. Nitrat (NO3)}

Adanya senyawa nitrat dalam air tanah menunjukan bahwa kemungkinan besar telah terjadi pencemaran terhadap air tanah. Air minum yang mengandung nitrat dalam jumlah banyak rasanya agak pahit (Fajarini, 2014). Hasil pengukuran kadar nitrat pada mata air Waipidi adalah 5,5 mg/L sedangkan standar kriteria baku mutu air PP nomor 82 tahun 2001 kelas I adalah $10 \mathrm{mg} / \mathrm{L}$ (Tabel 1). Kadar nitrat mata pada air Waipidi memenuhi standar kriteria baku mutu. Hal ini mengindikasikan bahwa bahan pencemar yang masuk ke badan mata air Waipidi masih tergolong rendah. Bahan pencemar tersebut dapat bersumber dari limbah hasil kegiatan pertanian terutama pemakaian pupuk nitrogen seperti pupuk kompos dan pupuk urea.

\section{g. Nitrit $\left(\mathrm{NO}_{2}\right)$}

Keberadaan nitrit menggambarkan berlangsungnya proses biologis perombakan bahan organik dengan oksigen terlarut sangat rendah. Sumber nitrit dapat berupa limbah industri dan limbah dosmetik serta penggunaan pupuk nitrogen (Effendi, 2003).

Hasil pengukuran kadar nitrit pada mata air Waipidi nilai nitrit adalah 0,049 mg/L sedangkan standar kriteria baku mutu air PP nomor 82 tahun 2001 kelas I adalah 0,06 $\mathrm{mg} / \mathrm{L}$ (Tabel 1). Kadar nitrit pada mata air Waipidi memenuhi standar kriteria baku mutu, disebabkan karena bahan pencemar yang masuk ke badan mata air masih tergolong rendah. Bahan pencemar tersebut dapat berasal dari limbah hasil kegiatan pertanian di sekitar mata air Waipidi seperti penggunaan pupuk nitrogen.

\section{h. Sianida (Cn)}

Senyawa sianida dikategorikan sebagai bahan beracun dan berbahaya. Oleh karena itu, keberadaan spesies ion sianida dalarn air perlu dipantau. Sianida dalam bentuk hidrogen sianida ( $\mathrm{HCN})$ dapat menyebabkan kematian yang sangat cepat jika dihirup dalam konsentrasi tertentu. Konsentrasi HCN yang fatal bagi manusia jika dihirup selama 10 menit adalah $546 \mathrm{mg} / \mathrm{L}$. Terpaparnya sianida pada tubuh manusia dapat menganggu sistem pernapasan, jantung, sistem pencernaan, sistem peredaran darah, dan sistem saraf Paparan HCN secara lama dalam konsentrasi tinggi dapat menstimulasi sistem saraf pusat yang kemudian diikuti oleh depresi, kejang-kejang, lumpuh, dan kematian (Pitoi, 2014).

Berdasarkan hasil analisis uji kualitas air pada mata air Waipidi nilai sianida adalah 0,14 mg/L sedangkan standar kriteria baku mutu air PP nomor 82 tahun 2001 kelas I adalah $0,02 \mathrm{mg} / \mathrm{L}$ (Tabel 1). Kadar sianida pada mata air Waipidi tidak memenuhi standar kriteria baku mutu. Kadar sianida yang tinggi dipengaruhi oleh keberadaan tumbuhan bambu di sekitar mata air yang mengandung kadar sianida, kemudian meresap masuk ke dalam badan mata air. Selain itu, kadar sianida dapat tercemar dari limbah cucian ubi kayu di sekitar aliran mata air yang meresap masuk kedalam badan mata air. Kadar sianida 
pada mata air Waipidi dikategorikan tidak memenuhi standar kriteria baku mutu air baik itu kelas I, II, III maupun IV. Mata air Waipidi tidak layak dimanfaatkan sebagai air minum, sehingga disarankan kepada masyarakat pengguna mata air Waipidi untuk tidak mengkonsumsi air tersebut karena kadar sianida yang tinggi pada suatu perairan sangat berbahaya dan dapat menjadi racun bagi tubuh jika dikonsumsi.

i. Mangan (Mn)

Tinggi rendahnya kadar mangan dalam air tanah dipengaruhi oleh kandungan oksigen yang terdapat dalam air tersebut, sedikitnya kandungan oksigen yang terdapat di dalam air tanah sehingga membentuk oksida yang menyebabkan unsur Mangan semakin terendap dan merubah warna air (Utomo dkk, 2016).

Berdasarkan hasil analisis uji kualitas air pada mata air Waipidi nilai mangan adalah 0,117 mg/L sedangkan standar kriteria baku mutu air PP nomor 82 tahun 2001 kelas I adalah $1 \mathrm{mg} / \mathrm{L}$ (Tabel 1). Kadar mangan pada mata air Waipidi tidak memenuhi standar kriteria baku mutu, disebabkan oleh faktor alami seperti pengikisan batuan yang ada di sekitar mata air Waipidi, juga disebabkan oleh struktur tanah lokasi mata air yang karst atau mengandung bebatuan. Kadar mangan pada mata air Waipidi dikategorikan tidak memenuhi standar kriteria baku mutu air baik itu kelas I, II, III, maupun IV. Pencemaran kadar mangan pada mata air Waipidi sudah melebihi ambang batas sehingga disarankan kepada masyarakat pengguna mata air ini, untuk tidak mengkonsumsi air tersebut karena dapat menimbulkan gangguan kesehatan.

j. Fosfat $\left(\mathrm{PO}_{4}{ }^{3-}\right)$

Sumber alami fosfat di perairan berasal dari pelapukan batuan mineral dan dekomposisi bahan organik. Fosfat juga dapat berasal dari sumber-sumber antropogenik seperti aktivitas transportasi, industri pembakaran sampah limbah pertanian dan limbah rumah tangga (Effendi, 2003).

Berdasarkan hasil analisis uji kualitas air pada mata air Waipidi nilai fosfat adalah 0,54 mg/L sedangkan standar kriteria baku mutu air PP nomor 82 tahun 2001 kelas I adalah 0,2 $\mathrm{mg} / \mathrm{L}$ (Tabel 4.1). Kadar fosfat pada mata air Waipidi tidak memenuhi standar baku mutu air. Kadar fosfat yang tinggi pada mata air Waipidi diduga disebabkan oleh buangan limbah yang berasal dari daerah pertanian, pembusukan pohon dan daun-daun serta pengikisan batuan yang ada di sekitar badan mata air Waipidi. Selain itu diduga dapat berasal dari hasil pembakaran sampah di sekitar lokasi mata air Waipidi. Kadar fosfat pada mata air Waipidi dikategorikan masuk dalam kriteria baku mutu air kelas III. Mata air Waipidi tidak layak digunakan sebagai air minum, sehingga disarankan kepada masyarakat untuk tidak mengkonsumsi air tersebut karena dapat menimbulkan gangguan kesehatan jika dikonsumsi secara terus-menerus.

\section{k. Klorida (Cl)}

Klorida banyak ditemukan di alam, hal ini karena sifatnya yang mudah larut. Selain itu, ion klorida bersenyawa dengan ion natrium menyebabkan air menjadi asin. Secara alami klorida masuk dalam badan berasal dari air laut yang masuk melalui air hujan (Sutrisno, 2007 dalam Sinaga, 2016).

Berdasarkan hasil analisis uji kualitas air pada mata air Waipidi nilai klorida adalah 0,24 mg/L sedangkan standar kriteria baku mutu air PP nomor 82 tahun 2001 kelas I adalah $0,03 \mathrm{mg} / \mathrm{L}$ (Tabel 1). Kadar klorida pada mata air Waipidi tidak memenuhi standar kriteria baku mutu. Peningkatan kadar klorida pada mata air Waipidi, terjadi secara alami disebabkan oleh masuknya air hujan pada badan mata air. Kadar klorida pada mata air Waipidi dikategorikan masuk dalam kriteria baku mutu air kelas IV. Mata air Waipidi tidak layak dimanfaatkan sebagai air minum karena dapat menimbulkan penyakit.

\section{Sulfat $\left(\mathrm{SO}_{4}^{-2}\right)$}

Kepekatan sulfat mencapai 1 hingga $5 \mathrm{mg} / \mathrm{l}$ pada kawasan air yang mempunyai keasaman rendah. Sedangkan pada kawasan air yang mempunyai keasaman tinggi, kepekatan sulfatnya tinggi. Jumlah ion sulfat yang berlebih dalam air minum menyebabkan terjadinya efek cuci perut pada manusia. Selain itu, Kehadiran sulfat dapat menimbulkan masalah bau dan korosi pada pipa air buangan akibat reduksi (Boyd, 1990 dalam Miefthawati, 2014). 


\section{Indigenous Biologi \\ Jurnal pendidikan dan Sains Biologi \\ Volume 2(2) 2019 (57-64)}

Berdasarkan hasil analisis uji kualitas air pada mata air Waipidi nilai sulfat adalah 7 mg/L sedangkan standar kriteria baku mutu air PP nomor 82 tahun 2001 kelas I adalah 400 $\mathrm{mg} / \mathrm{L}$ (Tabel 1). Kadar sulfat pada mata air Waipidi memenuhi standar kriteria baku mutu, disebabkan karena mata air Waipidi belum tercemar oleh buangan yang berasal dari limbah industri maupun sisa-sisa pakan ternak yang masuk dalam badan mata air.

\section{Parameter Biologi}

Pemeriksaan air secara biologis sangat penting untuk mengetahui keberadaan mikroorganisme yang terdapat dalam air. Bakteri coliform merupakan indikator kontaminasi lingkungan atau sanitasi yang kurang baik. Berbagai jenis bakteri patogen dapat ditemukan dalam sistem penyediaan air bersih, walaupun dalam konsentrasi yang rendah. Bakteri ini dapat diidentifikasi melalui metode MPN. Semakin tinggi tingkat kontaminasi bakteri coliform, semakin tinggi pula risiko kehadiran bakteri bakteri patogen lain yang biasa hidup dalam kotoran manusia dan hewan (Aryanta, 2001). Bakteri coliform yang terkandung dalam sampel air dapat mengindikasikan bahwa sampel air tercemar oleh tinja. Air yang tercemar oleh bakteri coliform menyebabkan pencemaran air oleh bakteri $E$. Coli, yang dapat mengganggu pencernaan (Doyle dkk, 2006 dalam Mukarromah, 2016).

Berdasarkan hasil analisis uji kualitas air pada mata air Waipidi nilai coliform adalah $\leq 1,8$ ml, sedangkan standar kriteria baku mutu air PP nomor 82 tahun 2001 kelas I adalah 1000 ml. Mata air Waipidi memenuhi standar kriteria baku mutu. Hal ini disebabkan oleh jarak antara tempat pembuangan kotoran manusia dengan mata air yang letaknya berjauhan, sehingga resiko tercemar oleh bakteri coliform masih sangat rendah.

\section{Kesimpulan}

\section{PENUTUP}

Berdasarkan hasil analisis uji kualitas air pada Mata Air Waipidi dengan perbandingan Baku Mutu Kelas I PP Nomor 82 Tahun 2001 dapat disimpulkan bahwa mata air Waipidi tidak memenuhi persyaratan standar baku mutu air kelas I. Beberapa parameter kimia yang melebihi ambang batas yaitu: DO, besi, mangan, tembaga, klorin, fosfat dan sianida sehingga mata air Waipidi tidak layak dimanfaatkan sebagai air minum. Mata air Waipidi dikategorikan masuk dalam standar baku mutu air kelas II yaitu dapat digunakan untuk prasarana/sarana rekreasi air, pembudidayaan ikan air tawar, peternakan dan mengairi tanaman.

\section{Saran}

1. Adanya sosialisasi dari pihak Pemerintah Kabupaten Sumba tengah tentang kualitas air bersih terutama yang berkaitan dengan penggunaan air dari mata air Waipidi kepada masyarakat .

2. Pemerintah Kabupaten Sumba Tengah diharapkan untuk merumuskan suatu kebijakan tentang penggunaan air dari mata air Waipidi yang disosialisasikan kepada Masyarakat karena pencemaran kualitas air pada mata air Waipidi yang sudah melebihi ambang batas apa sehingga tidak layak dimanfaatkan sebagai air minum

3. adanya penelitian lanjutan yang mengkaji tentang identifikasi jenis-jenis bakteri pada di mata air Waipidi

\section{UCAPAN TERIMA KASIH}

Ucapan terima kasih Penulis sampaikan kepada :

1. Bapak Frederikus M. Nanga, SP, selaku Kepala Dinas Lingkungan Hidup Kabupaten Sumba Tengah dan semua rekan-rekan kerja Dinas Lingkungan Hidup yang sudah membantu melancarkan proses penelitian mulai dari awal penelitian hingga selesainya penelitian dengan baik.

2. Bapak/lbu Dosen Pembimbing dan Penguji, Teman-teman penelitian yang sudah membantu Penulis menyelesaikan artikel ini.

\section{DAFTAR PUSTAKA}

Achmad, R.2004. Kimia Lingkungan. Yogyakarta. Andi Offset. 
Aryanta, N. 2001. Penuntun Praktikum Mikrobiologi. Institut Teknologi Bandung.

Badan Standardisasi Nasional. 2004.SNI 06-6989.3-2004.Air dan Air Limbah Cara Uji Kadar TSS dan TDS secara Gravimetri. BSN.

Badan Standardisasi Nasional.2005. SNI 06-6989.23-2005 Air dan air limbah-Bagian 23: Cara uji suhu dengan termometer.Serpong:BSN.

Badan Standardisasi Nasional. 2005. SNI 06-6989.27-2005. Air dan air limbah bagian-27:Cara uji kadar padatan terlarut total secara gravimetri.BSN.

Effendi. 2003. Telaah Kualitas Air Bagi Pengelolaan Sumber Daya Dan Lingkugan. Kanisius. Yogyakarta.

Fajarini, S. 2014. Analisis Kualitas Air Tanah Masyarakat di Sekitar Tempat Pembuangan Akhir (TPA) Sampah, Kelurahan Sumur Batu Bantar Gebang. Skripsi. Program Studi Kesehatan Masyarakat Fakultas Kedokteran dan IImu Kesehatan. Universitas Islam Negeri Syarif Hidayatullah. Bekasi.

Hach Methode, 8146, 8506, 8507, 8039, 8027, 8149, 8048, 8021, 8051, Powder Pillow. Catalog Number DOC022.53.00725. DR 2800 Spectrophotometer procedures manual. June, 2007. Edition 2. Hach Company, 2007. All rights reserved.Printed in Germany. Joko, T. 2010. Unit Produksi Dalam Sistem Penyediaan Air Minum. Graha Ilmu. Yogjakarta.

Mantawali, S, L. 2012. Uji Kualitas Air Sumur Gali Pada Topografi Tanah Miring dan Tanah Datar Dilihat Dari Bakteri Coliform Dan Escherichia coli di Desa Pilohayanga Barat Kecamatan Telaga Kabupaten Gorontalo. Jurnal Kesehatan Lingkungan. Program Studi Kesehatan Masyarakat Peminatan Kesehatan Lingkungan, Fakultas IImu Kesehatan dan Keolahragawan.Universitas Negeri Gorontalo.

Miefthawati, P. 2014 Analisa Penentuan Kualitas Air Tasik Bera di Pahang Malaysia Berdasarkan Pengukuran Parameter Fisika-Kimia. Jurnal Sains, Teknologi dan Industri. Teknik Elektro, Fakultas Sains dan Teknologi, UIN Suska Riau.

Mukaromah, R. 2016. Analisis Sifat Fisis Dalam Studi Kualitas Air Di Mata Air Sumber Asem Dusun Kali Jeruk, Desa Siwuran Kecamatan Garung Kabupaten Wonosobo. Skripsi. Program Studi Fisika. FMIPA Universitas Negeri Semarang.

Peraturan Pemerintah RI No.82 Tahun 2001. Pengolahan Kualitas Air Dan Pengendalian Pencemaran Air. Kementrian Lingkungan Hidup. Jakarta.

Pitoi, M. 2014. Sianida, Klasifikasi, Toksisitas, Degradasi, Analisis (StudiPustaka). Jurnal MIPA Unsrat Online.Jurusan kimia, FMIPA. Unsrat. Manado.

Salmin. (2000). Kadar Oksigen Terlarut di Perairan Sungai Dadap, Goba, Muara Karang dan Teluk Banten. Dalam : Foraminifera Sebagai Bioindikator Pencemaran, Hasil Studi di Perairan Estuarin Sungai Dadap, Tangerang (Djoko P. Praseno, Ricky Rositasari dan S. Hadi Riyono, eds.) P3O - LIPI hal 42 - 46.

Sinaga, E. 2016. Penetapan Kadar Klorida Pada Air Minum Isi Ulang Dengan Metode Argentometri. Skripsi. Fakultas Farmasi Program studi Diploma III Analisis Farmasi dan Makanan. Uiversitas Sumatera Utara. Medan.

Suryani, 2004. Lingkungan, Sumber Daya Alam dan Lingkungan. Yogyakarta.

Utomo, N dan Jati, R. 2016. Analisis Dan Identifikasi Status Mutu Air Tanah di Kota Singkawang Studi Kasus Kecamatan Singkawang Utara. Jurnal Teknik Lingkungan. Program Studi Teknik Lingkungan Jurusan Teknik Sipil Fakultas Teknik Universitas Tanjungpura. Pontianak.

Waluyo, L. 2007. Mikrobiologi Umum. UMM Press. Malang. 